\title{
CORRECTION
}

\section{Correction to: Comparison of three surgical techniques for internal angular dermoid cysts: a randomized controlled trial}

Mostafa M. Diab (D), Richard C. Allen, Ayman E. Abdel Ghafar and Kareem B. Elessawy (D)

(c) The Author(s), under exclusive licence to The Royal College of Ophthalmologists 2021

Eye (2022) 36:2369; https://doi.org/10.1038/s41433-021-01915-1

Correction to: Eye https://doi.org/10.1038/s41433-021-01851-0, published online 20 November 2021
In part Objective scar visibility (patient's eyes open) and part Stony Brook Scar evaluation (patient's eyes closed) the Kruskal-Wallis test was named incorrectly as chi-square test.

The original article has been corrected. 